\title{
Activation of death-associated protein kinase 1 promotes neutrophil apoptosis to accelerate inflammatory resolution in acute respiratory distress syndrome
}

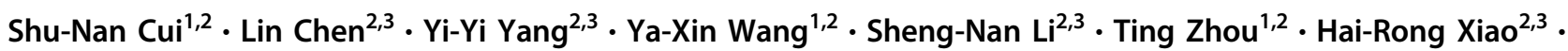 \\ Lu Qin ${ }^{2,3} \cdot$ Wen Yang ${ }^{2,3} \cdot$ Shi-Ying Yuan ${ }^{1,2} \cdot$ Shang-Long Yao ${ }^{2,3} \cdot$ You Shang ${ }^{1,2}$
}

Received: 2 May 2018 / Revised: 30 January 2019 / Accepted: 1 February 2019 / Published online: 25 March 2019

(c) United States \& Canadian Academy of Pathology 2019

\begin{abstract}
Acute respiratory distress syndrome (ARDS) is a uniform progression of overwhelming inflammation in lung tissue with extensive infiltration of inflammatory cells. Neutrophil apoptosis is thought to be a significant process in the control of the resolution phase of inflammation. It has been proved that 5-Aza-2'-deoxycytidine (Aza) can inhibit cancer by activating death-associated protein kinase 1 (DAPK1) to promote apoptosis. However, the effect of DAPK1 on neutrophil apoptosis is unclear, and research on the role of Aza in inflammation is lacking. Here, we investigated whether Aza can regulate DAPK1 expression to influence the fate of neutrophils in ARDS. In vitro, we stimulated neutrophil-like HL-60 (dHL-60) cells with different concentrations of Aza for different durations and used RNA interference to up- or downregulate DAPK1 expression. We observed that culturing dHL-60 cells with Aza increased apoptosis by inhibiting NF- $\mathrm{kB}$ activation to modulate the expression of Bcl-2 family proteins, which was closely related to the levels of DAPK1. In vivo, ARDS was evoked by intratracheal instillation of lipopolysaccharide (LPS; $3 \mathrm{mg} / \mathrm{kg}$ ). One hour after LPS administration, mice were treated with Aza (1 mg/kg, i.p.). To inhibit DAPK1 expression, mice were intraperitoneally injected with a DAPK1 inhibitor. Aza treatment accelerated inflammatory resolution in LPS-induced ARDS by suppressing pulmonary edema, alleviating lung injury and decreasing the infiltration of inflammatory cells in bronchoalveolar lavage fluid (BALF). Moreover, Aza reduced the production of proinflammatory cytokines. However, administration of the DAPK1 inhibitor attenuated the protective effects of Aza. Similarly, the proapoptotic function of Aza was prevented when DAPK1 was inhibited either in vivo or in vitro. In summary, Aza promotes neutrophil apoptosis by activating DAPK1 to accelerate inflammatory resolution in LPS-induced ARDS. This study provides the first evidence that Aza prevents LPS-induced neutrophil survival by modulating DAPK1 expression.
\end{abstract}

Supplementary information The online version of this article (https:// doi.org/10.1038/s41374-019-0242-9) contains supplementary material, which is available to authorized users.

\section{Introduction}

Acute respiratory distress syndrome (ARDS) is a major cause of acute respiratory failure, which may lead to multiple organ failure [1]. Lung injury is primarily caused by neutrophil-dependent damage to the lung endothelium and epithelium related to severe hypoxemia and carbon dioxide

Medical College, Huazhong University of Science and Technology, Wuhan, China

2 Institute of Anesthesiology and Critical Care Medicine, Union Hospital, Tongji Medical College, Huazhong University of Science and Technology, Wuhan, China

3 Department of Anesthesiology, Union Hospital, Tongji Medical College, Huazhong University of Science and Technology, Wuhan, China 
retention caused by protein-rich pulmonary edema [2]. Inflammatory cascades characterized by complicated processes play significant roles in ARDS [3]. The first step of the inflammatory cascades is the induction phase, which then leads to the peak of inflammation [3]. In response to exogenous or endogenous danger signals, the induction phase of the acute inflammatory response causes rapid immune activation, which is beneficial for host defense [4]. Such immune activation leads to tissue injury followed by the migration of immune cells into the tissue [4]. In the lung, acute inflammation is notable for its vascular response involving hyperemia [5]. Although there are several mechanisms to increase vascular permeability, neutrophildependent lung injury is probably one of the most important pathways $[2,6]$. The next step is the resolution phase, which is self-controlled. If the inflammation persists and fails to resolve, it will lead to chronic inflammatory disease [5]. For successful restoration of injured lung tissue, the excessive neutrophils must be removed, and the subsequent neutrophil influx must be stopped. When neutrophils suffer from apoptosis, they are rapidly engulfed by macrophages; this process is dependent on the expression of phosphatidylserine on apoptotic cells, which is recognized by the macrophages [5, 7]. In addition, some polyunsaturated fatty acid-derived proresolving lipid mediators can downregulate chemokine receptors such as CXCR2 to block neutrophil recruitment [4]. In short, inflammatory resolution is necessary to limit inflammation and restore tissue homeostasis.

Clinical data analysis and animal studies have shown that the excessive accumulation of neutrophils drives the development of ARDS [6, 8]. Apoptosis is considered an effective pathway to eliminate activated neutrophils in inflammatory tissue. Under normal circumstances, clearance of the invading pathogens encourages the rapid apoptosis of neutrophils [9]. Many mediators, such as interleukin 8 (IL8), interleukin 1 (IL-1), and tumor necrosis factor (TNF), can suppress neutrophil apoptosis, leading to the prolonged survival of neutrophils [10]. The delay of neutrophil apoptosis allows a large number of activated neutrophils to accumulate in the lung microvasculature and interstitium and persist for a long time; these neutrophils mainly release several toxic factors, such as reactive oxygen species, proteinases, and neutrophil extracellular traps, which can result in the sustained disruption of the endothelial-epithelial barrier [11]. As a result, the fate of neutrophils is one of the significant factors determining negative or positive consequences in lung tissue. Neutrophil apoptosis is thought to be an important control point in the resolution of inflammation.

5-Aza-2'-deoxycytidine (Aza), an inhibitor of DNA methyltransferase (DNMT), is effective for the treatment of acute myelogenous leukemia through the modulation of cell growth or death and has the potential to be used for other antitumor therapies [12]. A close correlation between inflammation and carcinogenesis has been shown in epidemiological studies; for example, it has been reported that an estimated $20-25 \%$ of all cases of cancer worldwide are related to inflammation induced by infection $[13,14]$. Therefore, we suppose that Aza may have the capacity to affect the process of inflammation. However, the actions of Aza in regulating inflammatory resolution remain unclear. Death-associated protein kinase 1 (DAPK1), a serinethreonine protein kinase, widely participates in various modes of cell death triggered by interferon-gamma (IFN- $\gamma$ ), tumor necrosis factor-alpha (TNF- $\alpha$ ), Fas, and transforming growth factor-beta (TGF- $\beta$ ) [15-17]. Studies have shown that demethylation with Aza can promote apoptosis in osteosarcoma cells and colon cancer cells by restoring the transcription of DAPK1 to suppress tumor metastasis $[18,19]$. However, the role of DAPK1 in modulating neutrophil apoptosis is unclear. Recently, DAPK1 has been identified to modulate inflammation in various ways, but its role in regulating inflammation is controversial. On the one hand, DAPK1 is involved in the composition of the NLRP3 inflammasome, which is required for the development of inflammation [20, 21]. On the other hand, DAPK1 inhibits the secretion of interleukin 6 (IL-6) by inhibiting the activation of signal transducer and activator of transcription 3 (STAT3), which is beneficial for alleviating the inflammatory response [22]. Here, we investigated the ability of DAPK1 to regulate neutrophil apoptosis and further explored whether Aza can accelerate inflammatory resolution in ARDS by modulating DAPK1 expression.

\section{Materials and methods}

\section{Neutrophil-like cell culture}

The neutrophil-like cells were differentiated from HL-60 cells (CCTCC, Wuhan, China) according to the methods in previous studies [23-25]. Briefly, the cells were cultured in Roswell Park Memorial Institute (RPMI) 1640 medium supplemented with $10 \%$ fetal bovine serum (FBS) and $1 \%$ penicillin and streptomycin in a humidified environment with $5 \% \mathrm{CO}_{2}$ at $37^{\circ} \mathrm{C}$. The HL-60 cells were cultured with $1 \mathrm{mM}$ all-trans retinoic acid for 5 days, and neutrophil-like HL-60 (dHL-60) cells were obtained. The cells were passaged once every third day and were used for experiments during the exponential growth phase.

\section{RNA interference and cell transfection}

DAPK1 small interfering RNA (siRNA) was purchased from RiboBio (Guangzhou, China). The DAPK1 $\Delta \mathrm{CaM}^{-1-}$ plasmid was obtained from the Pathology Laboratory of 
Tongji Medical College of Huazhong University of Science and Technology. dHL-60 cells were cultured in six-well plates at a concentration of $1.5 \times 10^{5}$ cells $/ \mathrm{ml}$ for $24 \mathrm{~h}$. Before incubation with Aza (Sigma-Aldrich, St. Louis, MO, USA), the cells were preincubated with the dissolved DAPK1 siRNA for $12 \mathrm{~h}$ to reduce the level of DAPK1 expression. The same dose of a control siRNA (RiboBio) was also preincubated with cells in parallel for $12 \mathrm{~h}$. To increase the level of DAPK1 expression in the cells, dHL60 cells were cultured in six-well plates $\left(5 \times 10^{5}\right.$ cells/well $)$ and then transfected with DAPK1 $\Delta \mathrm{CaM}^{-1-}$ plasmid or control plasmid using Lipofectamine 2000 transfection reagent (Invitrogen, Carlsbad, CA, USA) according to the manufacturer's instructions.

\section{Assessment of apoptosis in vitro}

Apoptosis was determined by flow cytometry. Cells were cultured in six-well plates, harvested, and then counted and resuspended in phosphate-buffered saline (PBS). To determine the proportion of apoptotic cells among all cells, an annexin V-fluorescein isothiocyanate (FITC)/propidium iodide (PI) apoptosis detection kit (KeyGen BioTech, Jiangsu, China) was used according to the manufacturer's instructions. Cytoplasmic histone-associated DNA fragments (Roche, Laval, Quebec, Canada) were detected to assay DNA cleavage in apoptotic cells. Briefly, cytoplasmic histone-associated DNA fragments from cells were extracted and incubated in a microtiter plate coated with an antihistone antibody. Subsequently, after color development, the samples were read at $405 \mathrm{~nm}$ using a microplate reader. The DNA strand breaks generated during apoptosis were analyzed by terminal deoxynucleotidyl transferase-mediated dUTP nick end labeling (TUNEL; Roche, Mannheim, Germany). Cells were harvested and washed 3 times in PBS. Then, the cell density was adjusted to $2 \times 10^{6}$ cells $/ \mathrm{ml}$. A $100 \mu \mathrm{l}$ aliquot of the cell suspension was transferred to a slide, and the air-dried cell samples were incubated in the TUNEL reaction mixture for $1 \mathrm{~h}$ at $37^{\circ} \mathrm{C}$. Then, the cells were stained with 4',6-diamidino-2-phenylindole (DAPI) for $\sim 5 \mathrm{~min}$. Images were captured with an Olympus fluorescence microscope (Olympus, Tokyo, Japan) by an investigator who was blinded to the group.

\section{Western blotting analysis}

Whole extracts from dHL-60 cells and mouse neutrophils were obtained using a protein extraction reagent kit (KeyGen BioTech). Proteins were separated by sodium dodecyl sulfate-polyacrylamide gel electrophoresis (SDS-PAGE) on a $10 \%$ SDS gel and then transferred to a polyvinylidene fluoride membrane. The membranes were blocked with 5\% nonfat milk for $1 \mathrm{~h}$. Next, the membranes were probed with
anti-DAPK1 (Sigma-Aldrich), anti-NF- $\mathrm{kB}$ p65, antiphospho-NF-kB p65, anti-Bcl-2, anti-Bax (Santa Cruz, California, USA), anti-phospho-DAPK1 (Cell Signaling Technology, Danvers, MA, USA), or GAPDH antibodies (Antgene Biotechnology, Wuhan, China) overnight at $4{ }^{\circ} \mathrm{C}$. The membranes were then incubated with horseradish peroxidase (HRP)-conjugated secondary antibodies (1:3000 dilution; Antgene Biotechnology) for $60 \mathrm{~min}$ at room temperature. All proteins were detected by SuperSignal ECL. The band intensities were analyzed by ImageJ (version 1.45s; National Institutes of Health, Bethesda, MD, USA).

\section{Murine ARDS}

Male C57BL/6J mice (aged 6-8 weeks; Hua Fu Kang Co, Beijing, China) weighing 20-24 g were reared in a specific pathogen-free environment with fixed temperature and humidity. All animal experiments were approved by the Animal Care and Use Committee of Tongji Medical College of Huazhong University of Science and Technology. The ARDS model was evoked by intratracheal instillation of lipopolysaccharide (LPS; Sigma-Aldrich) at a dose of $3 \mathrm{mg} / \mathrm{kg}$. One hour after LPS administration, mice were treated with Aza (1 mg/kg, i.p.) or normal saline (NS; $0.1 \mathrm{ml} /$ mouse, i.p.). On days $0,1,2,4$, and 7, the lungs were lavaged or harvested without lavage. To investigate whether Aza could regulate inflammatory resolution by modulating DAPK1 expression, a DAPK1 inhibitor (MCE, Deer Park, NJ, USA) was used in other animal experiments. Mice were randomly assigned to a sham group (NS), a vehicle group (LPS), an Aza group (LPS + Aza), a DAPK1 inhibitor (DI) group (DAPK1 inhibitor + LPS) and an Aza + DI group (DAPK1 inhibitor + LPS + Aza). Before intratracheal instillation of LPS $(3 \mathrm{mg} / \mathrm{kg})$, the mice in the DI and Aza + DI groups were intraperitoneally injected with the DAPK1 inhibitor $(1 \mathrm{mg} / \mathrm{kg} / \mathrm{day})$ for 14 days, while the mice in the vehicle and Aza groups were intraperitoneally injected with $10 \%$ dimethyl sulfoxide (DMSO; $0.15 \mathrm{ml} /$ mouse/day) for 14 days before LPS-induced ARDS. One hour after LPS instillation, the mice in the Aza + DI group and the Aza group received Aza $(1 \mathrm{mg} / \mathrm{kg}$, i.p.). The mice were sacrificed $24 \mathrm{~h}$ after LPS administration, and samples were collected for analysis.

\section{Histopathological analysis and cell count}

After anesthetization by intraperitoneal injection of $1 \%$ pentobarbital $(50 \mathrm{mg} / \mathrm{kg})$, the mice were sacrificed at the indicated times. The left lung tissues were fixed by inflation with $4 \%$ paraformaldehyde and were embedded in paraffin for hematoxylin and eosin staining. The sections were examined for pulmonary pathology under a microscope, and lung injury scores were calculated according to the official criteria [26] by an investigator blinded to the group. 


\section{Total cell count and differential count}

Bronchoalveolar lavage fluid (BALF) was collected and centrifuged for $8 \mathrm{~min}$ at $1500 \mathrm{rpm}$ to obtain cells. Then, total cell counts were determined with a hematocytometer, and differential counts were measured after Giemsa staining. For the classification of leukocytes, at least three slides were chosen, and more than 300 cells were counted per slide.

\section{Assessment of protein concentration and cytokines in BALF}

The exudative protein in BALF was measured using a BCA protein assay kit (Thermo Fisher Scientific, Waltham, MA, USA). Enzyme-linked immunosorbent assays (ELISAs) were performed on BALF using kits for TNF- $\alpha$, IL-1 $\beta$, IL6, MCP-1, and IL-10 (ELISA kit, RayBiotech, Inc. Norcross, GA, USA).

\section{Peripheral blood neutrophil isolation}

A MACS system and a mouse neutrophil isolation kit (Miltenyi Biotec, Teterow, Germany) were used to isolate neutrophils by negative selection. Whole blood was collected from eight mice from the same group and lysed with red blood cell (RBC) lysis buffer (Miltenyi Biotec). The cells were resuspended in buffer and then incubated with a neutrophil biotin-antibody cocktail for $10 \mathrm{~min}$ at $4{ }^{\circ} \mathrm{C}$. After washing once in buffer, the cell pellets were incubated with Anti-Biotin MicroBeads (Neutrophil Isolation Kit, Miltenyi Biotec) for $15 \mathrm{~min}$ at $4{ }^{\circ} \mathrm{C}$. Then, the cell pellets were washed at $300 \times g$ for $10 \mathrm{~min}$, and the suspension was passed through an MS Column (Miltenyi Biotec). The unlabeled cells representing enriched neutrophils were collected.

\section{Assessment of neutrophil apoptosis in BALF}

After the BALF was harvested, the total cells were washed 3 times. Then, the cell density was adjusted to $3 \times 10^{6}$ cells/ $\mathrm{ml}$, and $200 \mu \mathrm{l}$ of the suspension was added to a tube for flow cytometric analysis. An APC anti-mouse Ly-6G antibody and a FITC anti-mouse annexin $\mathrm{V}$ antibody (eBioscience, San Diego, CA, USA) were used to label apoptotic neutrophils. Cytoplasmic histone-associated DNA fragments (Roche) were detected to assay DNA cleavage in the apoptotic cells.

\section{Immunohistochemistry}

Paraffin sections of lung tissues were dewaxed in xylene and placed in citrate buffer ( $\mathrm{pH}$ 6.0) for repair. Then, the sections were incubated in a $3 \%$ hydrogen peroxide solution for $25 \mathrm{~min}$ at room temperature. After blocking with 5\% bovine serum albumin (BSA) for $20 \mathrm{~min}, 50 \mu \mathrm{l}$ of Ly-6G antibody dilution (1:100 dilution; BD Pharmingen, San Diego, CA, USA) was added to each section, and the sections were incubated overnight at $4{ }^{\circ} \mathrm{C}$. Then, a labeled secondary antibody (HRP-goat anti-rat $\operatorname{IgG}$ ) was added for $50 \mathrm{~min}$ at $4{ }^{\circ} \mathrm{C}$. After washing, $50 \mu \mathrm{l}$ of $3,3^{\prime}$-diaminobenzidine chromogen (DAB; Sigma-Aldrich) was added for staining, and hematoxylin solution (Sigma-Aldrich) was used for counterstaining.

\section{Statistical analysis}

The data are expressed as mean values \pm standard error of the mean (s.e.m.). Statistics were analyzed with GraphPad Prism 5 for Windows (San Diego, CA, USA). Multiple comparisons were analyzed using one-way ANOVA followed by Newman-Keuls post hoc test. The results in mice grouped by treatment and time were analyzed using twoway ANOVA followed by Bonferroni post hoc test. A level of $P<0.05$ was considered statistically significant.

\section{Results}

\section{Effects of Aza on dHL-60 cell apoptosis and DAPK1 expression}

To investigate the influence of Aza on apoptosis, we performed flow cytometry to quantify the apoptotic cells. To examine DNA fragmentation, cells were processed for a TUNEL assay, and a cytoplasmic histone-associated DNA fragment assay was also used. First, dHL-60 cells were stimulated with different concentrations of Aza $(0,1$, 2 , or $4 \mu \mathrm{M}$ ) for $72 \mathrm{~h}$. Our data showed that with increasing Aza concentrations, apoptosis, as measured by flow cytometry and DNA fragment and TUNEL assays, increased gradually and reached a maximum at $4 \mu \mathrm{M}$ Aza (Fig. 1a, c and e). Then, we stimulated cells for different durations. As shown in Fig. 1b, d and f, with increasing time, the number of annexin V-labeled cells and the amount of DNA fragments and TUNEL-positive cells increased gradually. Furthermore, Aza promoted the decline in dHL-60 cell viability in a dose- and timedependent manner, consistent with the results regarding apoptosis (Supplementary Fig. 1A, B). To determine whether Aza had an effect on DAPK1 expression, we performed western blotting analysis to assess changes in protein levels. The data showed that within the same duration of stimulation, DAPK1 expression increased in a dose-dependent manner. By contrast, the levels of phospho-DAPK1 (pDAPK1) decreased significantly (Fig. 1g). It has been reported that DAPK1 is negatively regulated by phosphorylation and that dephosphorylation 

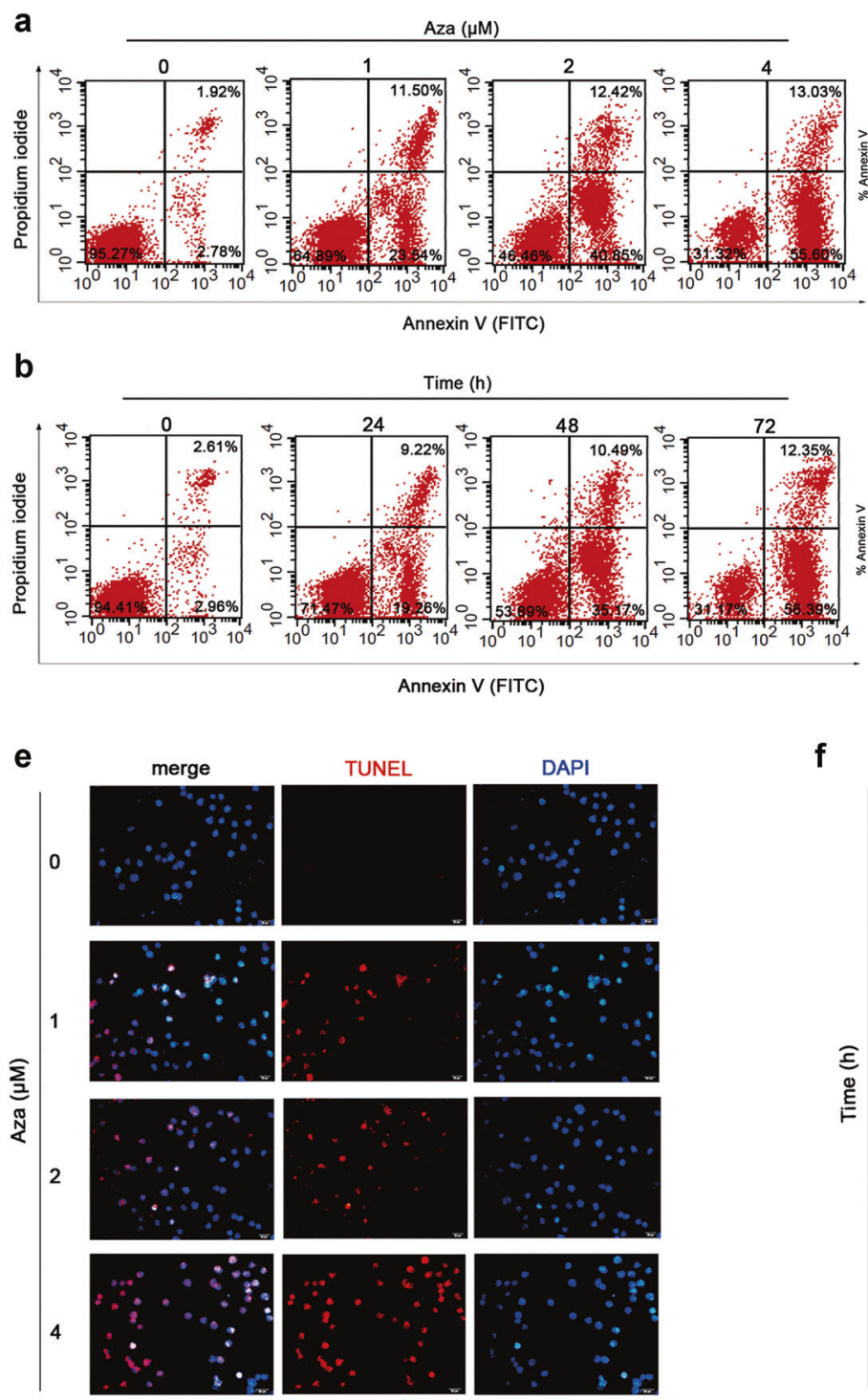

g
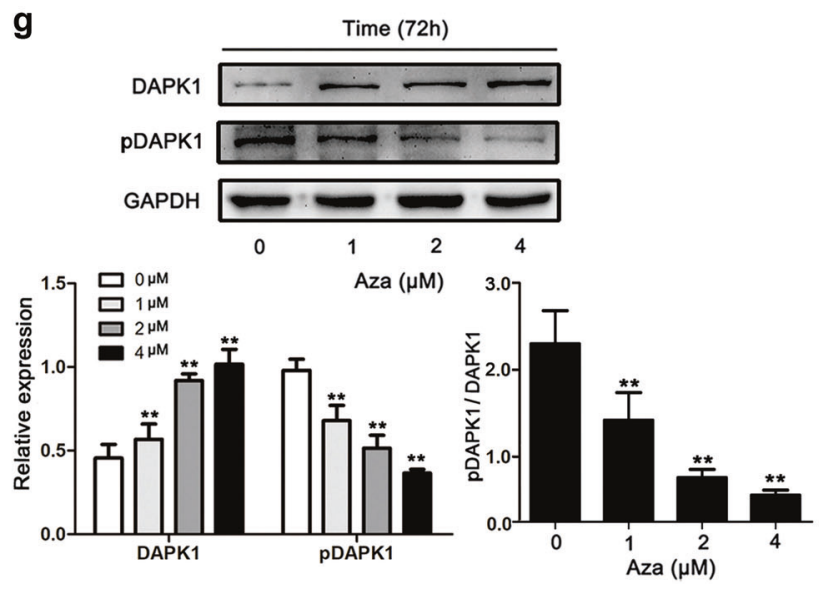

of Ser308 consequently promotes its catalytic activity [27]. Therefore, the data suggested that both the protein levels and the activity of DAPK1 were promoted by
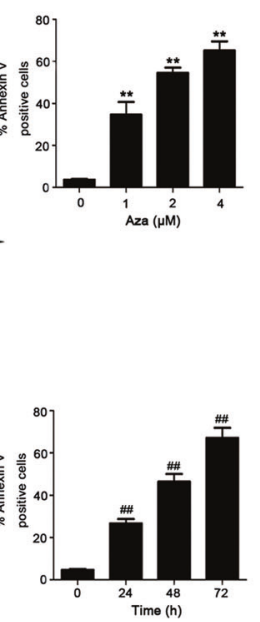

C

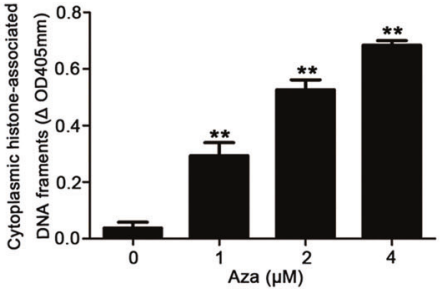

d

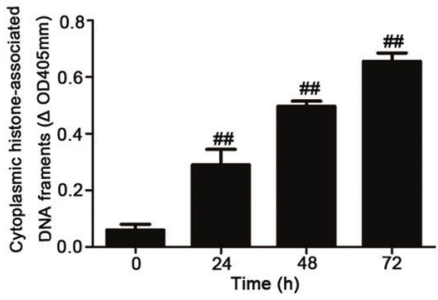

$\mathbf{f}$

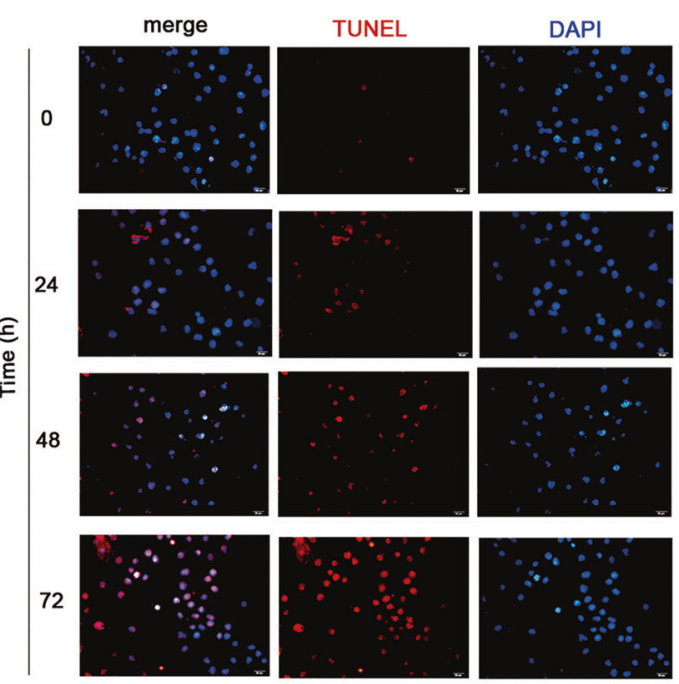

h
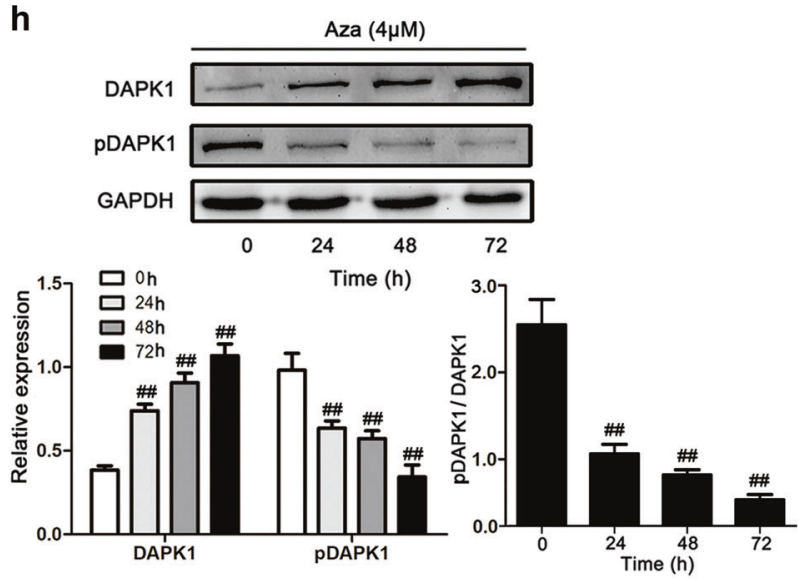

different concentrations of Aza. With increasing stimulation times, the protein levels and activity of DAPK1 increased gradually (Fig. 1h). 
Fig. 1 Effects of Aza on dHL-60 cell apoptosis and DAPK1 expression. dHL-60 cells were incubated with Aza $(0,1,2$, or $4 \mu \mathrm{M})$ for $72 \mathrm{~h}$. a Cells were labeled with annexin V (FITC) and PI to assess apoptosis using flow cytometry. c Cytoplasmic histone-associated DNA fragment assay. e TUNEL staining (scale bars: $20 \mu \mathrm{m}$ ). Cells were stimulated with Aza $(4 \mu \mathrm{M})$ for different durations $(0,24,48$, or $72 \mathrm{~h})$. Apoptosis was detected by flow cytometry (b), a cytoplasmic histoneassociated DNA fragment assay (d), and TUNEL staining (scale bars: $20 \mu \mathrm{m} ; \mathbf{f}$ ). The images shown are representative of three independent experiments. The data represent means \pm s.e.m. $(n=3$ per group). DAPK1 and pDAPK1 expression were analyzed by western blotting. g With increasing concentrations of Aza, both the protein levels and activity of DAPK1 increased gradually and reached a maximum at 4 $\mu \mathrm{M}$ Aza. $\mathbf{h}$ The protein levels and activity of DAPK1 increased with increasing stimulation time. GAPDH was used as a loading control, and the ratio of pDAPK1 to DAPK1 was also calculated. The images shown are representative of three independent experiments. The data represent the means \pm s.e.m. of three replicated experiments. ${ }^{* *} P<0.01$ vs. the $0 \mu \mathrm{M}$ group and ${ }^{\# \#} P<0.01$ vs. the $0 \mathrm{~h}$ group

\section{DAPK1 is essential for the induction of apoptosis by Aza}

To maximize the effects of Aza, we used $4 \mu \mathrm{M}$ Aza to stimulate dHL-60 cells for $72 \mathrm{~h}$ in subsequent experiments. We successfully transfected plasmid or siRNA into cells to up- or downregulate DAPK1 expression, respectively (Fig. 2a, b). When the DAPK1 $\Delta \mathrm{CaM}^{-/-}$plasmid was transfected into cells, Aza further promoted DAPK1 expression. However, when DAPK1 was inhibited by transfection with siRNA, Aza lost the capacity to elevate DAPK1 levels (Fig. 2c). Similarly, Aza reduced cell viability and promoted apoptosis dramatically in DAPK1overexpressing cells. However, the proapoptotic function of Aza was attenuated when DAPK1 was silenced (Fig. 2d-f and Supplementary Fig. 1C). All of these results indicated a significant role of DAPK1 in Aza-induced apoptosis. It has been reported that DAPK1 can inhibit lipopolysaccharide (LPS)-induced nuclear factor kappa B (NF- $\mathrm{KB}$ ) activation and the transcription of proinflammatory cytokines [28]. In addition, the transcription factor NF- $\mathrm{KB}$ p65 plays an important role in regulating genes that control many responses in immunocytes, including proliferation, cytoskeletal remodeling, and apoptosis [29]. Therefore, we investigated the significance of NF- $\kappa \mathrm{B}$ in Aza-regulated mechanisms of apoptosis. When DAPK1 was overexpressed in cells, Aza further decreased the levels of p-NF$\kappa \mathrm{B}$ p65. However, when DAPK1 was inhibited in cells by siRNA, Aza had no effect on p-NF-kB p65 (Fig. 2g). Next, we examined the expression of $\mathrm{Bcl}-2$ family proteins: the antiapoptotic protein $\mathrm{B}$-cell lymphoma-2 (Bcl-2) and the proapoptotic protein $\mathrm{Bcl}-2$ associated $\mathrm{X}$ (Bax). Our findings suggested that DAPK1 overexpression in cells enhanced the Aza-mediated suppression of Bcl-2 expression and promotion of Bax expression. However, inhibiting DAPK1 in cells prevented Aza from modulating Bax and Bcl-2 (Fig. 2g).
Aza accelerates inflammatory resolution in ARDS

Having shown a role of Aza in promoting apoptosis in vitro, we next examined the ability of Aza to modulate inflammatory resolution in ARDS. An ARDS model was evoked in C57BL/6J mice by intratracheal instillation of LPS at a dose of $3 \mathrm{mg} / \mathrm{kg}$. After LPS administration, pulmonary histopathological analysis showed important changes, including alveolar congestion, hemorrhage, hyaline membrane formation, increased thickness of the alveolar wall and infiltration of inflammatory cells, which were most noticeable on day 1 (Fig. 3a). In addition, the lung injury scores also reached a maximum on day 1 (Fig. 3b). The lung wet/dry weight and the amount of total protein in BALF, which reflect the degree of pulmonary edema, were dramatically increased on days 1 and 2 (Fig. 3c, d). The number of inflammatory cells in BALF reflects the severity of inflammation. As shown in Fig. 3e, f, after LPS instillation, the number of total cells and neutrophils increased dramatically, reaching a maximum at day 1 and then declining until returning to normal at day 7 . To investigate the proresolving action of Aza, one hour after LPS administration, mice were injected intraperitoneally with Aza. Our data showed that Aza attenuated lung injury, edema, and the infiltration of total inflammatory cells. The histopathological changes in Aza-treated mice were alleviated more rapidly than those in LPS-treated mice. Moreover, Aza decreased neutrophil accumulation in airways on day 1 , and the number of neutrophils had returned to normal on day 4 (Fig. 3f). On the other hand, Aza increased BALF monocyte/macrophage numbers dramatically on day 2, which was beneficial for reducing inflammation (Fig. $3 \mathrm{~g}$ ). We also examined the levels of cytokines in BALF on days 0 and 1 . The levels of proinflammatory cytokines, including TNF- $\alpha$, interleukin $1 \beta$ (IL-1 $\beta$ ), interleukin 6 (IL-6) and monocyte chemotactic protein 1 (MCP-1), were increased significantly after LPS administration on day 1 . As shown in Fig. $4 \mathrm{a}-\mathrm{d}$, the levels of these proinflammatory cytokines were lower in Aza-treated mice than in LPS-treated mice. Furthermore, Aza also promoted the production of the antiinflammatory cytokine interleukin 10 (IL-10) on day 1 (Fig. 4e). All these data indicated that Aza treatment suppressed the inflammatory response and accelerated inflammatory resolution in LPS-induced ARDS.

\section{Aza enhances DAPK1 expression to promote neutrophil apoptosis in LPS-induced ARDS}

The majority of neutrophils that accumulate in inflamed tissues arise from peripheral blood in the acute inflammatory response [30]. Because the number of neutrophils in BALF was not sufficient for western blotting analysis, we sorted peripheral neutrophils using magnetic beads to 
a
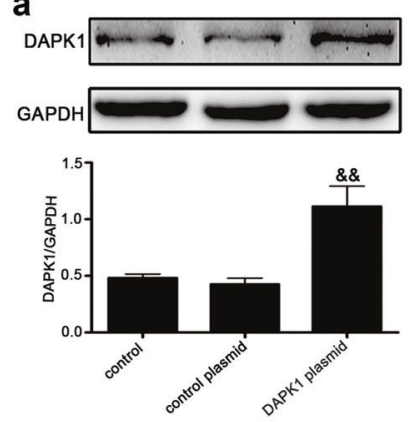

b
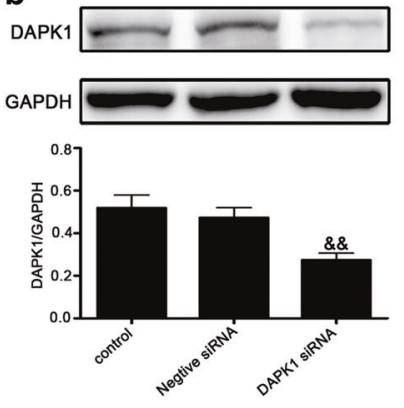

C
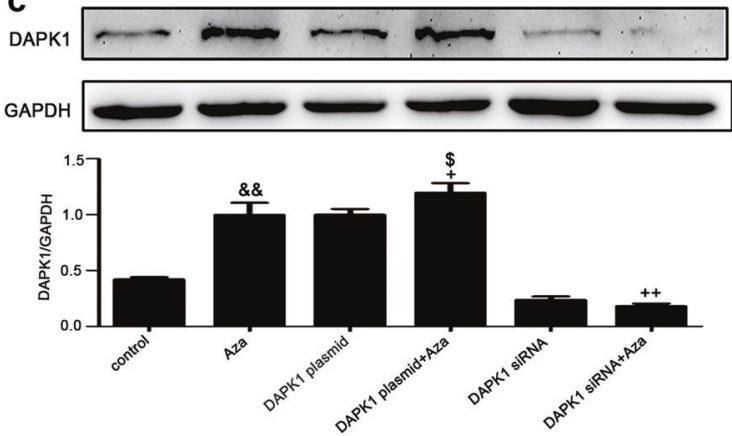

d
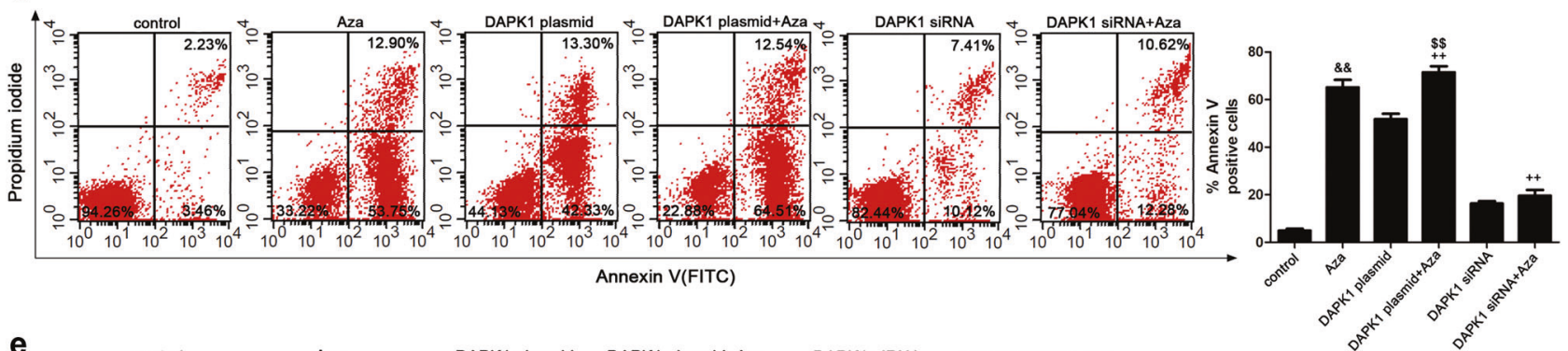

e
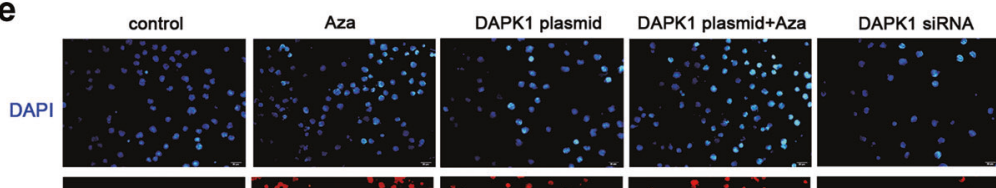

DAPK1 SiRNA+Aza
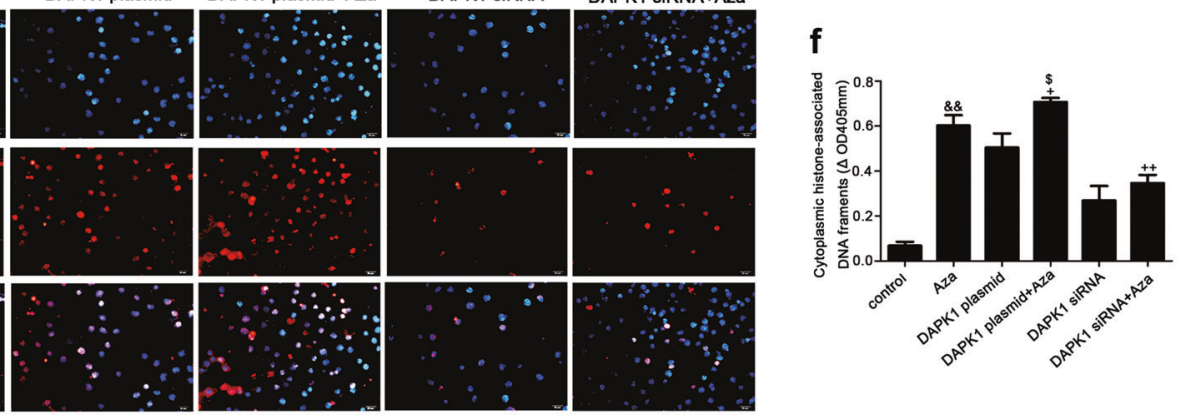

g
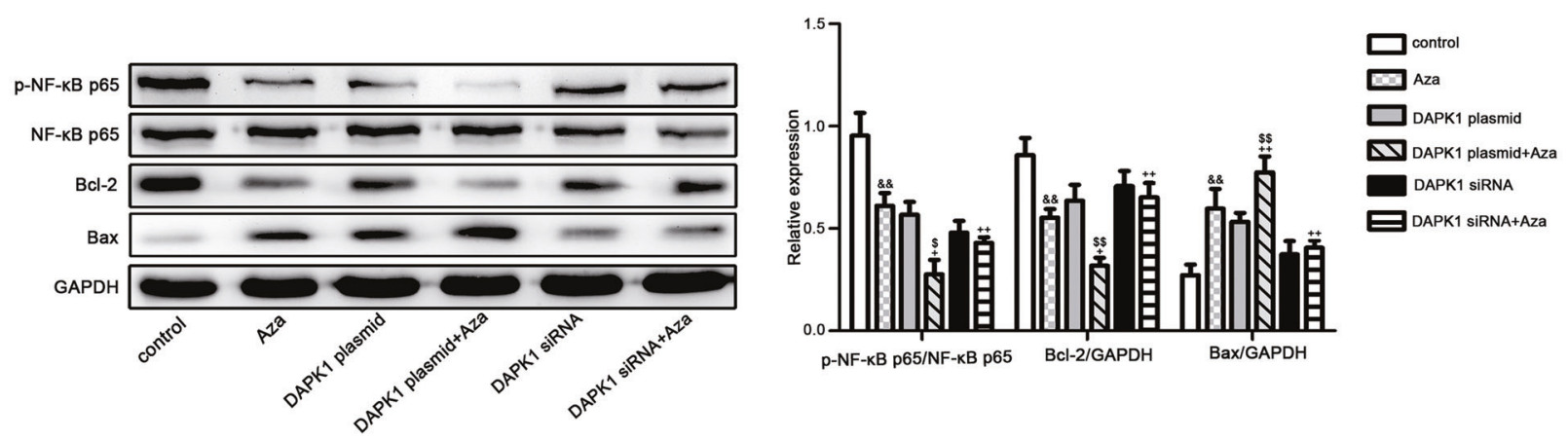

Fig. 2 DAPK1 is essential for the induction of apoptosis by Aza. a DAPK1 $\Delta \mathrm{CaM}^{-1-}$ plasmid (a) or DAPK1 siRNA (b) was transfected into dHL-60 cells, and DAPK1 expression was analyzed by western blotting. After successful transfection, the cells were stimulated with Aza $(4 \mu \mathrm{M})$ for $72 \mathrm{~h}$. c Aza further elevated the level of DAPK1 in DAPK1 $\Delta \mathrm{CaM}^{-l-}$ plasmid-transfected cells. However, the effect of Aza was attenuated in DAPK1 siRNA-transfected cells. GAPDH was used as a loading control. The images shown are representative of three independent experiments. The data are expressed as the means \pm s.e.m. of three replicated experiments. d Cells were labeled with annexin V (FITC) and PI to determine apoptosis using flow cytometry.

The data represent means \pm s.e.m. ( $n=4$ per group). The DNA fragments in apoptotic cells were detected by TUNEL staining (scale bars: $20 \mu \mathrm{m}$; e) and a cytoplasmic histone-associated DNA fragment assay (f). $\mathbf{g}$ Western blotting analysis of the expression of p-NF- $\mathrm{BB}$ p65, Bcl2 , and Bax. GAPDH and NF-kB p65 were used as loading controls. The image shown is representative of three independent experiments. The data are expressed as the means \pm s.e.m. of three replicated experiments. ${ }^{\& \&} P<0.01$ vs. the control group, ${ }^{\$} P<0.05$ vs. the DAPK1 plasmid group, ${ }^{\$} P<0.01$ vs. the DAPK1 plasmid group, ${ }^{+} P<0.05$ vs. the Aza group, and ${ }^{++} P<0.01$ vs. the Aza group 


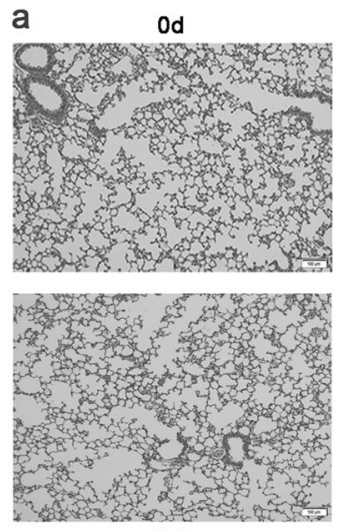

Od
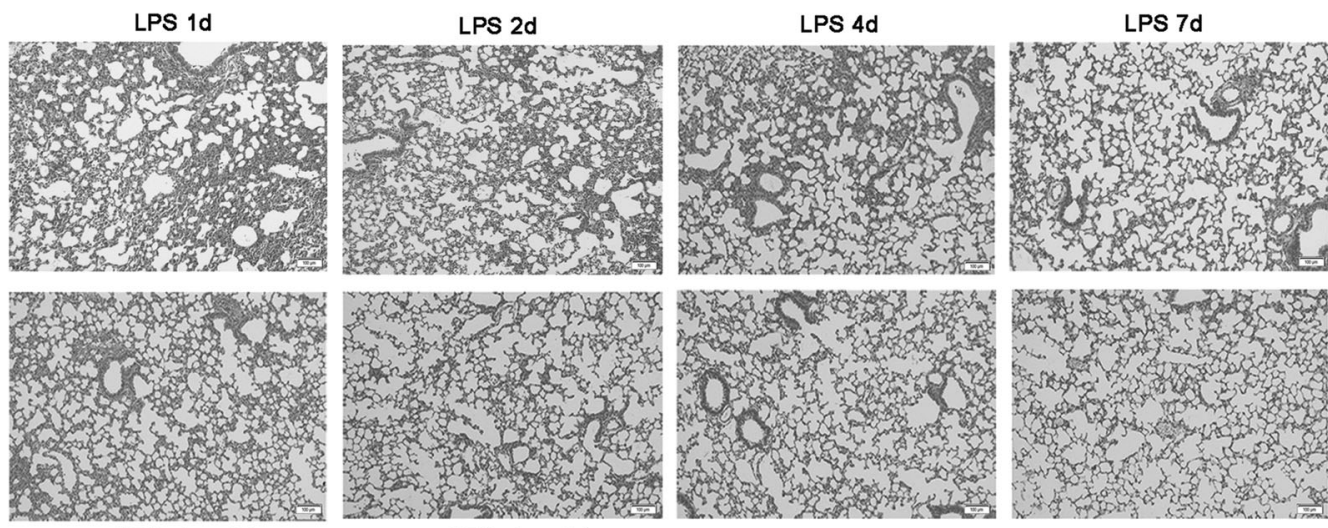

LPS+Aza 1d

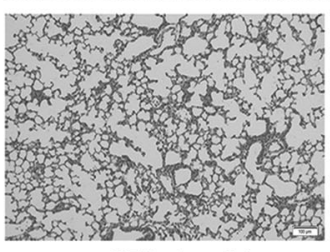

LPS+Aza 2d

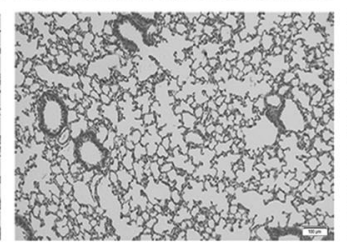

LPS+Aza 4d

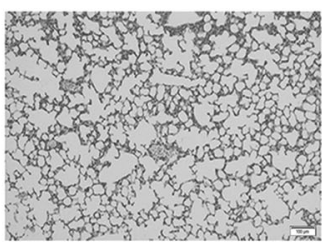

LPS+Aza 7d
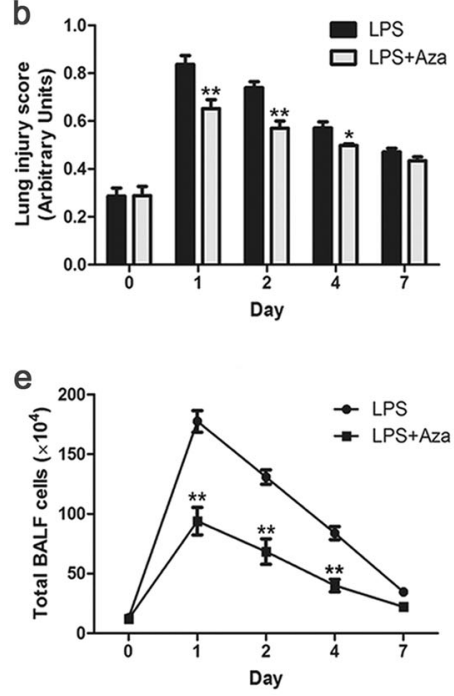
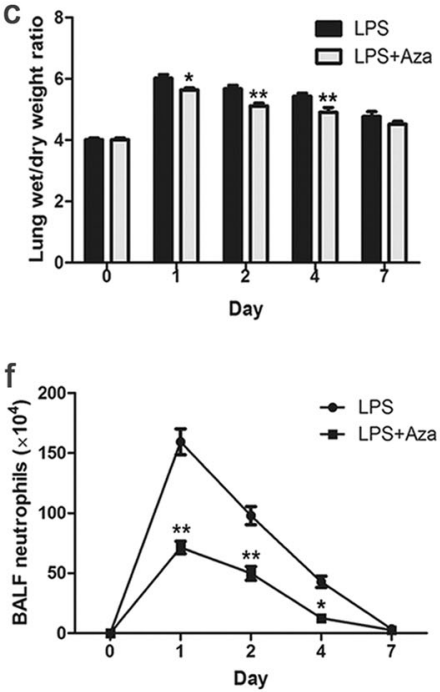
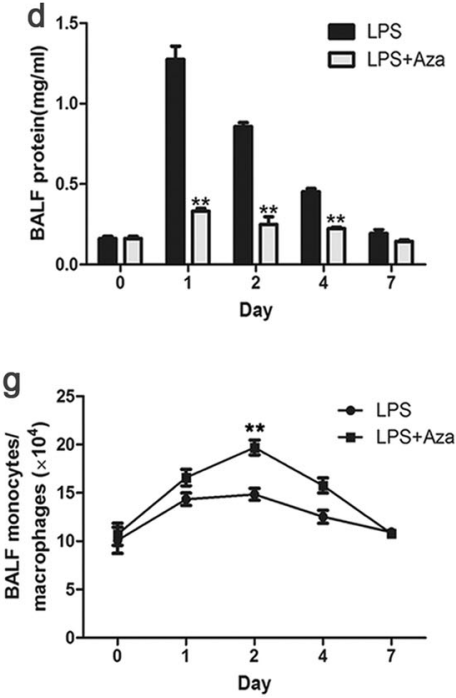

Fig. 3 Aza accelerates inflammatory resolution in ARDS. The ARDS model was evoked by intratracheal instillation of LPS $(3 \mathrm{mg} / \mathrm{kg})$. One hour after LPS administration, the mice were treated with Aza (1 mg/ $\mathrm{kg}$, i.p.) or NS (0.1 ml/mouse, i.p.). On days $0,1,2,4$, and 7 , mice were sacrificed, and the lungs were lavaged or harvested without lavage. a Hematoxylin and eosin staining (scale bars: $100 \mu \mathrm{m}$ ). b Lung injury scores. c Lung wet/dry ratios. d BALF protein. e Total BALF cells. f BALF neutrophils. $\mathbf{g}$ BALF monocytes/macrophages. The data are expressed as means \pm s.e.m. $\left(n=6-8\right.$ mice per group). ${ }^{*} P<0.05$ vs. the LPS group and ${ }^{* *} P<0.01$ vs. the LPS group analyze DAPK1 expression and thus evaluate the influence of Aza on DAPK1 expression in vivo, and we also indirectly assessed the relationship between DAPK1 and neutrophil apoptosis in BALF. As shown in Fig. 5a, Aza treatment distinctly enhanced DAPK1 expression compared with that in the LPS group. To assess neutrophil apoptosis in BALF, an APC anti-mouse Ly-6G antibody and FITC anti-mouse annexin $\mathrm{V}$ antibody were used to label apoptotic neutrophils. Cytoplasmic histone-associated DNA fragments were also detected. The data showed that the changes in apoptotic neutrophils were consistent with the changes in DAPK1 levels (Fig. 5b, c). Moreover, we also examined neutrophil accumulation in lung tissue using immunohistochemistry. The Ly-6G antibody-labeled cells in lung tissue appeared dark brown in the LPS group. However, the color was much lighter in the Aza-treated group (Fig. 5d). These results revealed that Aza treatment reduced neutrophil accumulation in the lung and increased the number of apoptotic neutrophils in airways. By contrast, treatment with a small-molecule inhibitor of DAPK1 suppressed neutrophil apoptosis and enhanced neutrophil accumulation in lung tissues. Our data demonstrated that Aza promoted neutrophil apoptosis by modulating DAPK1 expression in LPS-induced ARDS.

\section{A DAPK1 inhibitor attenuates the protective functions of Aza in LPS-induced ARDS}

To further confirm the relationship between Aza treatment and DAPK1 in LPS-induced ARDS, a small-molecule inhibitor of DAPK1 (DI) was administered in subsequent studies. Administration of DI attenuated the protective functions of Aza in alleviating pulmonary histopathological changes (Fig. 6a, b) and mitigating pulmonary edema 

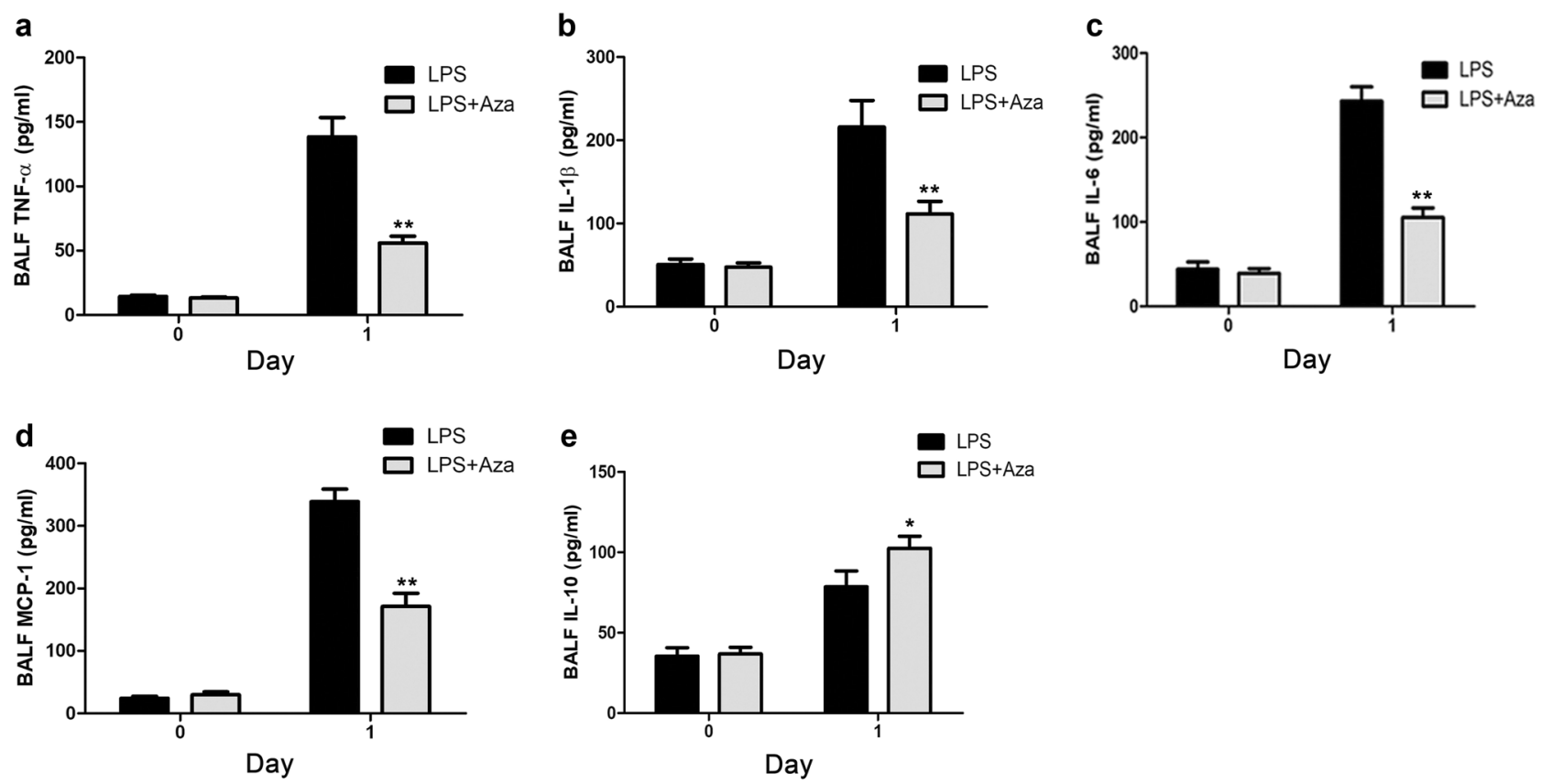

Fig. 4 Aza inhibits the production of proinflammatory cytokines and enhances the levels of anti-inflammatory cytokines in BALF. One hour after intratracheal instillation of LPS, mice were treated with Aza ( $1 \mathrm{mg} / \mathrm{kg}$, i.p.) or NS $(0.1 \mathrm{ml} / \mathrm{mouse}$, i.p.). On days 0 and 1 , the mice were sacrificed, and BALF was harvested. ELISA was used to assess

the levels of inflammatory cytokines. a BALF TNF- $\alpha$. b BALF IL-1 $\beta$. c BALF IL-6. d BALF MCP-1. e BALF IL-10. The data represent means \pm s.e.m. ( $n=6-8$ mice per group). ${ }^{*} P<0.05$ vs. the LPS group and ${ }^{* *} P<0.01$ vs. the LPS group

(Fig. 6c, d). We also observed an increase in the number of total cells and neutrophils in BALF in the Aza + DItreated group compared with that in the Aza-treated group (Fig. 6e, f). Similarly, the number of monocytes/macrophages in BALF was reduced in the Aza + DI group (Fig. 6g). Furthermore, we also observed higher levels of proinflammatory cytokines, such as TNF- $\alpha$, IL- $1 \beta$, IL- 6 , and MCP-1, and lower levels of the anti-inflammatory cytokine IL-10 in the Aza + DI-treated group than in the Aza-treated group (Fig. 7).

\section{Discussion}

Our results indicate that Aza can effectively induce neutrophil apoptosis by elevating DAPK1 expression in vitro. Furthermore, administration of Aza accelerated inflammatory resolution in LPS-induced ARDS by promoting neutrophil apoptosis in BALF and driving the clearance of neutrophils from lung tissue in vivo.

ARDS is a type of acute inflammatory injury leading to increased pulmonary vascular permeability and a loss of aerated lung tissue [31]. Improving gas exchange and preventing hypoperfusion are considered the major management strategies for ARDS [11]. Although supportive treatments and lung-protective ventilation can decrease the ARDS mortality rate to some extent, no statistically effective therapies for ARDS have been reported [1, 32, 33]. DNA methylation is an important epigenetic modification of the genome, and studies have shown that DNA methylation is partially responsible for developmental processes such as proliferation and differentiation [34] and may affect the penetrance of several diseases, such as cancer, neurological disorders [35, 36] and inflammatory diseases [37-39]. Therefore, we investigated an "epigenetic treatment", Aza, a kind of DNMT inhibitor, for LPS-induced ARDS. We developed a model of ARDS through intratracheal instillation of LPS at a dose of $3 \mathrm{mg} / \mathrm{kg}$, which produces selflimiting resolution of ARDS in a time-course model [40]. One day after LPS administration, a serious inflammatory response occurred that was characterized by the destruction of alveolar structure, pulmonary edema, and the infiltration of inflammatory cells. Treatment with Aza attenuated vascular permeability, promoted the removal of emigrated neutrophils, enhanced the accumulation of monocytes/ macrophages in airways and accelerated the recovery of pulmonary tissue to a normal state. Furthermore, Aza suppressed the production of some proinflammatory cytokines in airways. These results are consistent with the findings of previous studies that DNA methylation can regulate proinflammatory transcriptional factors along with the inflammatory genes that encode proinflammatory cytokines $[35,41]$. All of these data demonstrated that Aza could facilitate inflammatory resolution in LPS-induced ARDS. 
a
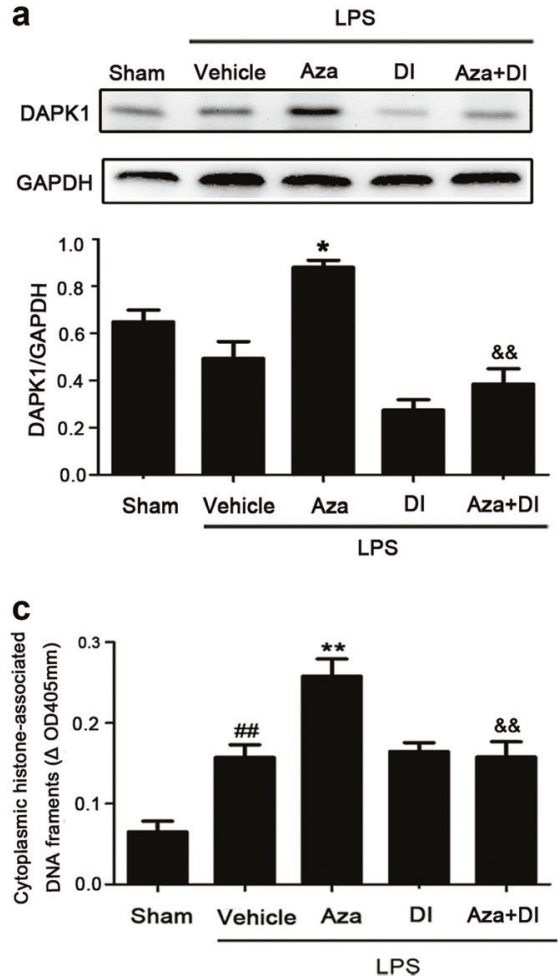

Fig. 5 Aza promotes neutrophil apoptosis in LPS-induced ARDS. Mice were intraperitoneally injected with a DAPK1 inhibitor $(1 \mathrm{mg} / \mathrm{kg} /$ day) or $10 \%$ DMSO $(0.15 \mathrm{ml} /$ mouse/day $)$ for 14 days. One hour after intratracheal instillation of LPS, the mice were treated with Aza $(1 \mathrm{mg} /$ $\mathrm{kg}$, i.p.) or $\mathrm{NS}(0.1 \mathrm{ml} / \mathrm{mouse}$, i.p. $)$. After $24 \mathrm{~h}$, the mice were sacrificed, and both peripheral blood and BALF were collected. a Peripheral neutrophils were sorted using magnetic beads. Western blotting revealed a significant increase in DAPK1 protein in the Aza-treated group, but DAPK1 expression was inhibited by the DAPK1 inhibitor in the DI and Aza + DI groups. A representative western blotting is shown. The data are shown as the means \pm s.e.m. of three independent

Based on the BALF cell counts and histopathological analyses, we speculate that neutrophils may have an effect on the resolution of inflammation.

Neutrophil apoptosis is regulated by complicated signaling pathways, such as those involving p38MAPK, Akt signals, and the Bcl-2 family [42-44]. The Bcl-2 family consists of protein members that either promote or inhibit apoptosis and is thus notable for regulating apoptosis. However, the exact mechanism by which the expression of the Bcl-2 family is controlled in neutrophil apoptosis is still unclear. Deathassociated protein kinase 1 (DAPK1) has been recognized as a tumor gene with the ability to increase the susceptibility of tumor cells to cell death signals [45, 46]. Studies have shown that Aza can induce apoptosis in multiple tumor cell types by upregulating DAPK1 expression [18, 19, 47]. Persistent inflammation resulting from infection or trauma may be involved in the onset of carcinogenesis [13]. Thus, we speculated that DAPK1 may participate in Aza-induced neutrophil apoptosis. To examine the molecular mechanism

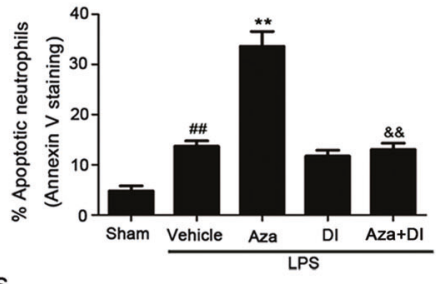

LPS
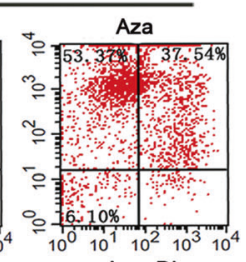

Aza+DI

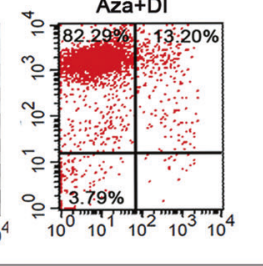

Annexin v (FITC)

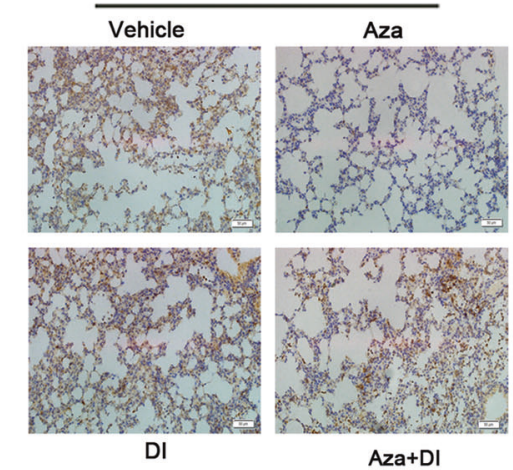

experiments. b Flow cytometry was used to determine the number of apoptotic neutrophils in BALF. Apoptotic cells were stained with both FITC annexin V and APC Ly-6G antibodies. c Cytoplasmic histoneassociated DNA fragments were assessed to further examine apoptotic neutrophils in BALF. d Immunohistochemistry images showing the Ly-6G antibody-stained total neutrophils that accumulated in lung tissue (scale bars: $50 \mu \mathrm{m}$ ). The neutrophils appear dark brown in color. The images shown are representative of three independent experiments. The data are expressed as means \pm s.e.m. $(n=6-8$ mice per group). ${ }^{\# \#} P<0.01$ vs. the sham group, ${ }^{*} P<0.05$ vs. the vehicle group, ${ }^{* *} P<0.01$ vs. the vehicle group, and ${ }^{\& \&} P<0.01$ vs. the Aza group

of neutrophil apoptosis in vitro, we used dHL-60 cells, which have a longer lifetime than human neutrophils. dHL-60 cells stimulated by Aza showed a significant increase in DAPK1 expression and a decrease in phosphorylated DAPK1. Furthermore, Aza promoted dHL-60 apoptosis in a dose- and time-dependent manner that was consistent with the effects on DAPK1 expression. These data demonstrated that Aza could promote neutrophil apoptosis by modulating the expression and activity of DAPK1 in vitro. Recent data have indicated that prolonged low expression of DAPK1 in T cells and monocytes is involved in NF-KB p65 activation [48, 49]. Thus, further studies should aim to elucidate the relationship between DAPK1 and the NF-kB p65-mediated Bcl-2 family. Our data showed that Aza suppressed phosphorylated NF- $\mathrm{KB}$ p65 expression and ameliorated the production of the downstream antiapoptotic protein $\mathrm{Bcl}-2$. By contrast, the production of the downstream proapoptotic protein Bax was upregulated by Aza. However, when DAPK1 was inhibited, the function of Aza was attenuated. All of these data indicated 
a LPS
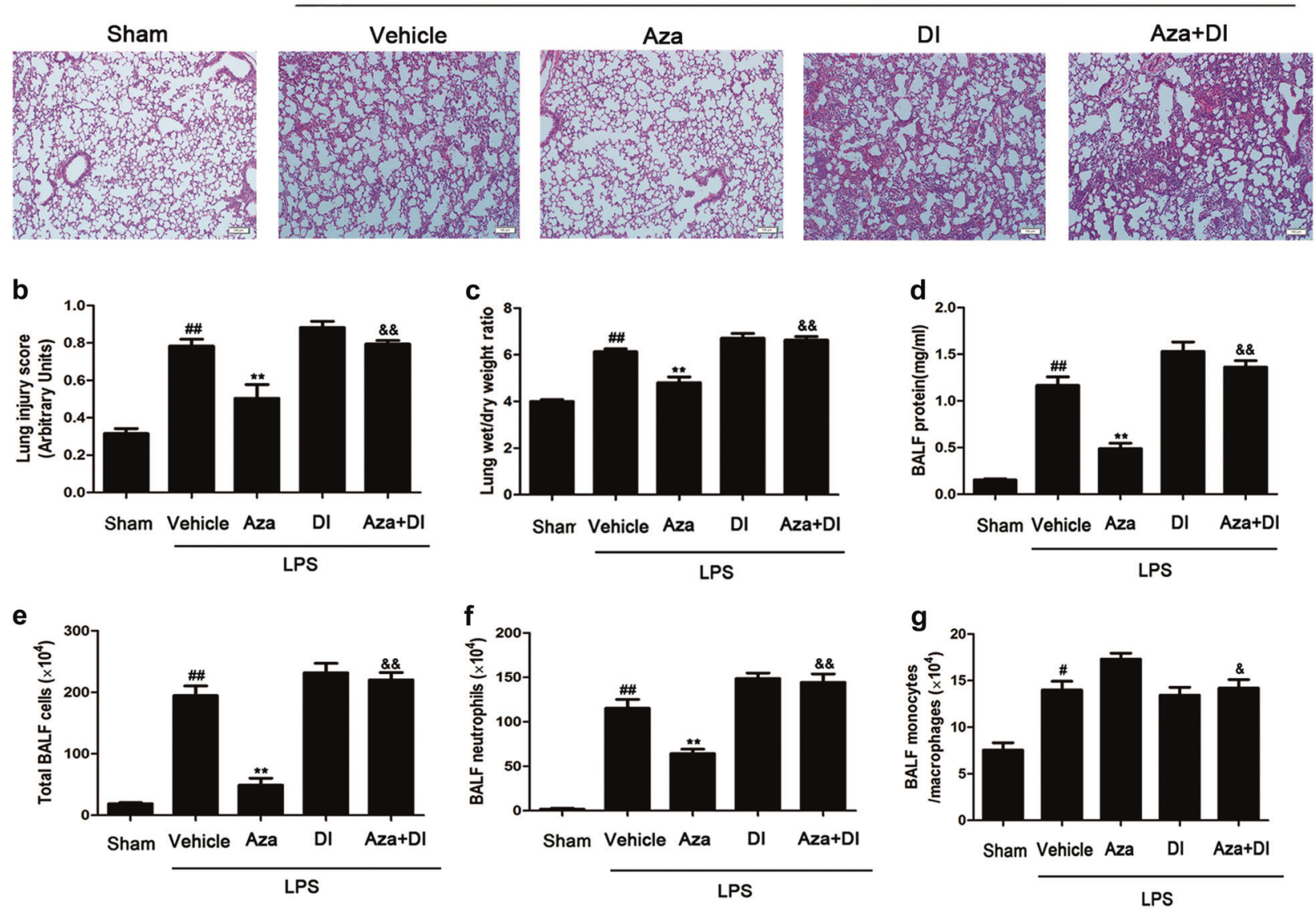

Fig. 6 A DAPK1 inhibitor attenuates the protective functions of Aza in LPS-induced ARDS. Mice were intraperitoneally injected with a DAPK1 inhibitor ( $1 \mathrm{mg} / \mathrm{kg} /$ day) or $10 \%$ DMSO $(0.15 \mathrm{ml} / \mathrm{mouse} /$ day $)$ for 14 days. One hour after intratracheal instillation of LPS, the mice were treated with Aza ( $1 \mathrm{mg} / \mathrm{kg}$, i.p.) or NS (0.1 ml/mouse, i.p.). After $24 \mathrm{~h}$, the mice were sacrificed, and the lungs were lavaged or harvested without lavage. a Hematoxylin and eosin staining (scale bars: $100 \mu \mathrm{m}$ ). b Lung injury scores. $\mathbf{c}$ Lung wet/dry ratios. d BALF protein. e Total BALF cells. f BALF neutrophils. g BALF monocytes/macrophages. The data are expressed as means \pm s.e.m. $(n=6-8$ mice per group). ${ }^{\#} P<0.05$ vs. the sham group, ${ }^{\# \#} P<0.01$ vs. the sham group, ${ }^{* *} P<0.01$ vs. the vehicle group, ${ }^{\&} P<0.05$ vs. the Aza group, and ${ }^{\& \&} P<0.01$ vs. the Aza group

proinflammatory activation of innate immune cells by inhibiting the production of proinflammatory cytokines and chemokines [46]. Moreover, DAPK1 can reduce the severity of chronic LPS-induced lung epithelial injury by inhibiting NF- $\kappa \mathrm{B}$ transcription in lung epithelial cells, which might contribute to its tumor-suppressor functions in epithelial carcinogenesis [48]. However, the role of DAPK1 in neutrophil apoptosis in the inflammatory resolution phase is unclear. Thus, we further explored the protective function of DAPK1 in Aza-treated mice. To harvest sufficient neutrophils to analyze DAPK1 expression, we sorted peripheral neutrophils from the different experimental groups using magnetic beads. The results demonstrated that Aza prominently increased DAPK1 expression in peripheral neutrophils, an effect that was consistent with the increased number of apoptotic neutrophils in BALF. By contrast, when DAPK1 expression was inhibited, the proapoptotic function of Aza was attenuated. To further confirm the 

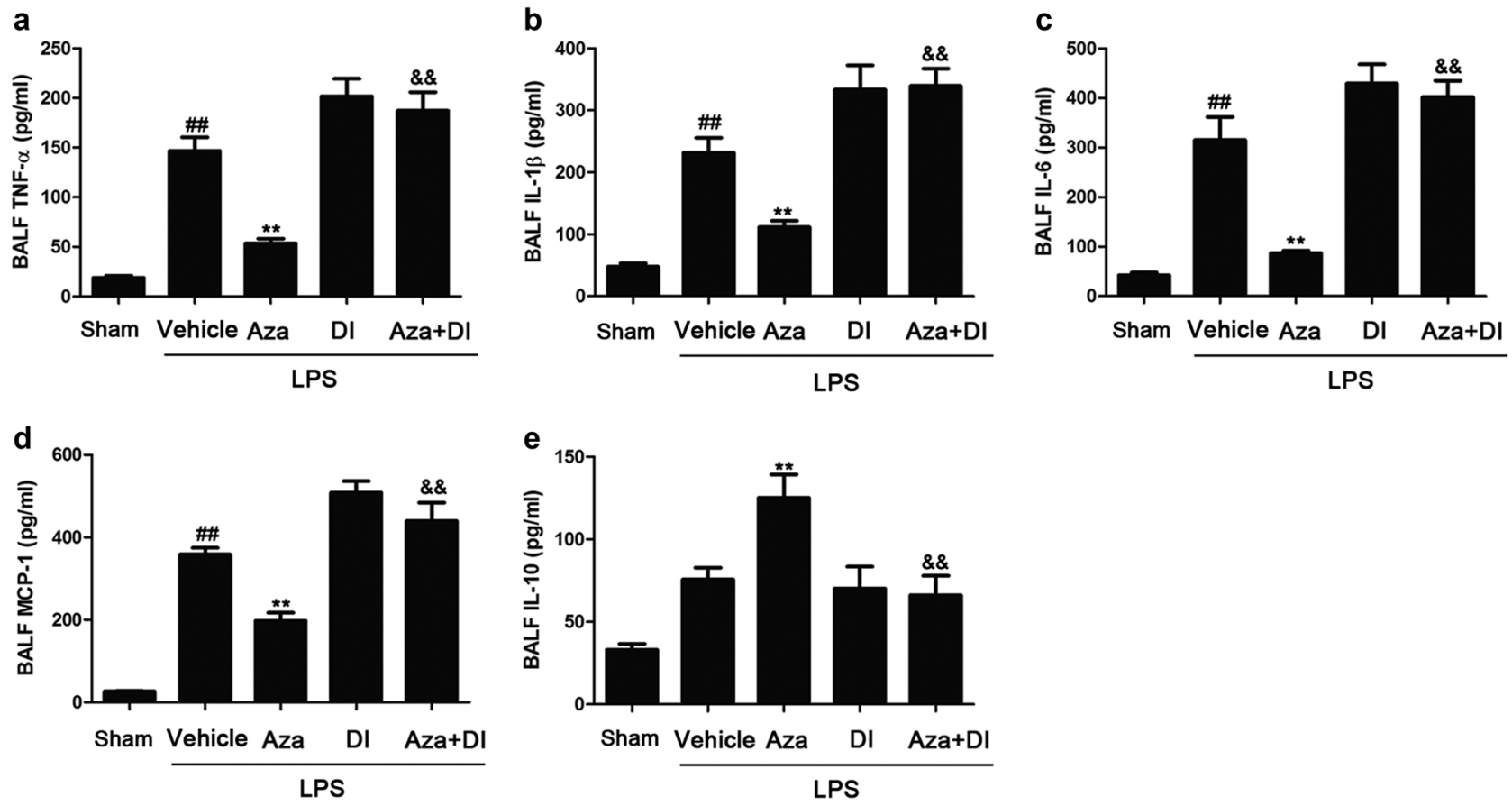

Fig. 7 Influence of DAPK1 inhibition on the production of inflammatory cytokines. Mice were intraperitoneally injected with a DAPK1 inhibitor $(1 \mathrm{mg} / \mathrm{kg} /$ day $)$ or $10 \%$ DMSO $(0.15 \mathrm{ml} / \mathrm{mouse} /$ day $)$ for 14 days. One hour after intratracheal instillation of LPS, the mice were treated with Aza (1 mg/kg, i.p.) or NS (0.1 ml/mouse, i.p.). After $24 \mathrm{~h}$, the mice were sacrificed, and BALF was collected. ELISA was used to

relationship between DAPK1 and Aza-mediated suppression of lung injury, a small-molecule inhibitor of DAPK1 was administered to inhibit DAPK1 expression in mice. Our data showed that the DAPK1 inhibitor partially attenuated the protective functions of Aza, such as the mitigation of histopathological changes, the reduction in lung edema, and the modulation of pro- and anti-inflammatory cytokines. These results provide more evidence for the positive role of DAPK1 in LPS-induced ARDS.

Taken together, our data demonstrate a novel mechanism in neutrophil apoptosis. In vitro, Aza promoted apoptosis by enhancing DAPK1 expression and activity. In vivo, Aza treatment accelerated inflammatory resolution in LPSinduced ARDS by upregulating DAPK1 expression, resulting in apoptosis of emigrated neutrophils. However, the exact epigenetic modification that occurs in the DAPK1 promoter region after administration of Aza has not been identified. Thus, more in-depth studies are needed to elucidate this mechanism. Our findings indicate that Aza may be a new agent for the treatment of ARDS. In addition, this study presents the first evidence that Aza prevents LPSinduced neutrophil survival by modulating DAPK1 expression. We emphasize that promoting neutrophil apoptosis to accelerate inflammatory resolution in ARDS is a potential therapeutic strategy.

assess the levels of inflammatory cytokines. a BALF TNF- $\alpha$. b BALF IL-1 $\beta$. c BALF IL-6. d BALF MCP-1. e BALF IL-10. The data are expressed as means \pm s.e.m. ( $n=6-8$ mice per group). ${ }^{\# \#} P<0.01$ vs. the sham group, ${ }^{* *} P<0.01$ vs. the vehicle group, and ${ }^{\& \&} P<0.01$ vs. the Aza group

Acknowledgements We are grateful for grants from the National Natural Science Foundation of China (nos. 81372036, 81671890, and 81601669).

\section{Compliance with ethical standards}

Conflict of interest The authors declare that they have no conflict of interest.

Publisher's note: Springer Nature remains neutral with regard to jurisdictional claims in published maps and institutional affiliations.

\section{References}

1. Matthay MA, Ware LB, Zimmerman GA. The acute respiratory distress syndrome. J Clin Invest. 2012;122:2731-40.

2. Matthay MA, Zemans RL. The acute respiratory distress syndrome: pathogenesis and treatment. Annu Rev Pathol. 2011;6:147-63.

3. Buckley CD, Gilroy DW, Serhan CN, Stockinger B, Tak PP. The resolution of inflammation. Nat Rev Immunol. 2013;13:59-66.

4. Schett G, Neurath MF. Resolution of chronic inflammatory disease: universal and tissue-specific concepts. Nat Commun. 2018; 9:3261.

5. Levy BD, Serhan CN. Resolution of acute inflammation in the lung. Annu Rev Physiol. 2014;76:467-92.

6. Williams AE, Chambers RC. The mercurial nature of neutrophils: still an enigma in ARDS? Am J Physiol Lung Cell Mol Physiol. 2014;306:L217-230. 
7. Kobayashi N, Karisola P, Pena-Cruz V, Dorfman DM, Jinushi M, Umetsu SE, et al. TIM-1 and TIM-4 glycoproteins bind phosphatidylserine and mediate uptake of apoptotic cells. Immunity. 2007;27:927-40.

8. Gill SE, Yamashita CM, Veldhuizen RA. Lung remodeling associated with recovery from acute lung injury. Cell Tissue Res. 2017;367:495-509.

9. Galani V, Tatsaki E, Bai M, Kitsoulis P, Lekka M, Nakos G, et al. The role of apoptosis in the pathophysiology of acute respiratory distress syndrome (ARDS): an up-to-date cell-specific review. Pathol Res Pract. 2010;206:145-50.

10. Martin TR, Nakamura M, Matute-Bello G. The role of apoptosis in acute lung injury. Crit Care Med. 2003;31:S184-188.

11. Yang CY, Chen CS, Yiang GT, Cheng YL, Yong SB, Wu MY, et al. New insights into the immune molecular regulation of the pathogenesis of acute respiratory distress syndrome. Int J Mol Sci. 2018;19:588.

12. Christman JK. 5-Azacytidine and 5-aza-2'-deoxycytidine as inhibitors of DNA methylation: mechanistic studies and their implications for cancer therapy. Oncogene. 2002;21:5483-95.

13. Okada F. Inflammation-related carcinogenesis: current findings in epidemiological trends, causes and mechanisms. Yonago Acta Med. 2014;57:65-72.

14. Loomis D, Grosse Y, Lauby-Secretan B, El Ghissassi F, Bouvard $\mathrm{V}$, Benbrahim-Tallaa L, et al. The carcinogenicity of outdoor air pollution. Lancet Oncol. 2013;14:1262-3.

15. Cohen O, Inbal B, Kissil JL, Raveh T, Berissi H, SpivakKroizaman T, et al. DAP-kinase participates in TNF-alpha- and Fas-induced apoptosis and its function requires the death domain. J Cell Biol. 1999;146:141-8.

16. Singh P, Ravanan P, Talwar P. Death associated protein kinase 1 (DAPK1): a regulator of apoptosis and autophagy. Front Mol Neurosci. 2016;9:46.

17. Nair S, Hagberg H, Krishnamurthy R, Thornton C, Mallard C. Death associated protein kinases: molecular structure and brain injury. Int J Mol Sci. 2013;14:13858-72.

18. Li Y, Geng P, Jiang W, Wang Y, Yao J, Lin X, et al. Enhancement of radiosensitivity by 5-Aza through activation of G2/M checkpoint response and apoptosis in osteosarcoma cells. Tumour Biol. 2014;35:4831-9.

19. Cho Y, Turner ND, Davidson LA, Chapkin RS, Carroll RJ, Lupton JR. Colon cancer cell apoptosis is induced by combined exposure to the n-3 fatty acid docosahexaenoic acid and butyrate through promoter methylation. Exp Biol Med. 2014;239:302-10.

20. Bauernfeind FG, Horvath G, Stutz A, Alnemri ES, MacDonald K, Speert D, et al. Cutting edge: NF-kappaB activating pattern recognition and cytokine receptors license NLRP3 inflammasome activation by regulating NLRP3 expression. J Immunol. 2009;183:787-91.

21. Jones HD, Crother TR, Gonzalez-Villalobos RA, Jupelli M, Chen S, Dagvadorj $J$, et al. The NLRP3 inflammasome is required for the development of hypoxemia in LPS/mechanical ventilation acute lung injury. Am J Respir Cell Mol Biol. 2014;50: 270-80.

22. Chakilam S, Gandesiri M, Rau TT, Agaimy A, Vijayalakshmi M, Ivanovska $\mathrm{J}$, et al. Death-associated protein kinase controls STAT3 activity in intestinal epithelial cells. Am J Pathol. 2013; 182:1005-20.

23. Gallagher R, Collins S, Trujillo J, McCredie K, Ahearn M, Tsai S, et al. Characterization of the continuous, differentiating myeloid cell line (HL-60) from a patient with acute promyelocytic leukemia. Blood. 1979;54:713-33.

24. Sarabhai T, Peter C, Bar AK, Windolf J, Relja B, Wesselborg S, et al. Serum alpha-1 antitrypsin (AAT) antagonizes intrinsic apoptosis induction in neutrophils from patients with systemic inflammatory response syndrome. PLoS ONE. 2017;12:e0177450.
25. Yamagishi A, Tanabe K, Yokokawa M, Morimoto Y, Kinoshita M, Suzuki H. Microfluidic device coupled with a microfabricated oxygen electrode for the measurement of bactericidal activity of neutrophil-like cells. Anal Chim Acta. 2017;985:1-6.

26. Matute-Bello G, Downey G, Moore BB, Groshong SD, Matthay MA, Slutsky AS, et al. An official American Thoracic Society workshop report: features and measurements of experimental acute lung injury in animals. Am J Respir Cell Mol Biol. 2011;44:725-38.

27. Fujita Y, Yamashita T. Role of DAPK in neuronal cell death. Apoptosis. 2014;19:339-45.

28. Lai MZ, Chen RH. Regulation of inflammation by DAPK. Apoptosis. 2014;19:357-63.

29. de Castro Barbosa ML, da Conceicao RA, Fraga AGM, Camarinha BD, de Carvalho Silva GC, Lima AGF, et al. NF-kappaB signaling pathway inhibitors as anticancer drug candidates. Anticancer Agents Med Chem. 2017;17:483-90.

30. Robb CT, Regan KH, Dorward DA, Rossi AG. Key mechanisms governing resolution of lung inflammation. Semin Immunopathol. 2016;38:425-48.

31. Ranieri VM, Rubenfeld GD, Thompson BT, Ferguson ND, Caldwell E, Fan E, et al. Acute respiratory distress syndrome: the Berlin Definition. JAMA. 2012;307:2526-33.

32. Antonelli M, Bonten M, Cecconi M, Chastre J, Citerio G, Conti G, et al. Year in review in Intensive Care Medicine 2012: III. Noninvasive ventilation, monitoring and patient-ventilator interactions, acute respiratory distress syndrome, sedation, paediatrics and miscellanea. Intensive Care Med. 2013;39:543-57.

33. Guerin C, Reignier J, Richard JC, Beuret P, Gacouin A, Boulain $\mathrm{T}$, et al. Prone positioning in severe acute respiratory distress syndrome. N Engl J Med. 2013;368:2159-68.

34. Samanta S, Rajasingh S, Cao T, Dawn B, Rajasingh J. Epigenetic dysfunctional diseases and therapy for infection and inflammation. Biochim Biophys Acta. 2017;1863:518-28.

35. Portela A, Esteller M. Epigenetic modifications and human disease. Nat Biotechnol. 2010;28:1057-68.

36. Castillo-Fernandez JE, Spector TD, Bell JT. Epigenetics of discordant monozygotic twins: implications for disease. Genome Med. 2014;6:60.

37. Thangavel J, Samanta S, Rajasingh S, Barani B, Xuan YT, Dawn $\mathrm{B}$, et al. Epigenetic modifiers reduce inflammation and modulate macrophage phenotype during endotoxemia-induced acute lung injury. J Cell Sci. 2015;128:3094-105.

38. Thangavel J, Malik AB, Elias HK, Rajasingh S, Simpson AD, Sundivakkam PK, et al. Combinatorial therapy with acetylation and methylation modifiers attenuates lung vascular hyperpermeability in endotoxemia-induced mouse inflammatory lung injury. Am J Pathol. 2014;184:2237-49.

39. Singer BD, Mock JR, Aggarwal NR, Garibaldi BT, Sidhaye VK, Florez MA, et al. Regulatory $\mathrm{T}$ cell DNA methyltransferase inhibition accelerates resolution of lung inflammation. Am J Respir Cell Mol Biol. 2015;52:641-52.

40. Gong J, Liu H, Wu J, Qi H, Wu ZY, Shu HQ, et al. Maresin 1 prevents lipopolysaccharide-induced neutrophil survival and accelerates resolution of acute lung injury. Shock. 2015;44:371-80.

41. Bayarsaihan D. Epigenetic mechanisms in inflammation. J Dent Res. 2011;90:9-17.

42. Sarkar A, Moller S, Bhattacharyya A, Behnen M, Rupp J, van Zandbergen G, et al. Mechanisms of apoptosis inhibition in Chlamydia pneumoniae-infected neutrophils. Int J Med Microbiol. 2015;305:493-500.

43. Choi KS, Park JT, Dumler JS. Anaplasma phagocytophilum delay of neutrophil apoptosis through the p38 mitogen-activated protein kinase signal pathway. Infect Immun. 2005;73: 8209-18.

44. Dyugovskaya L, Polyakov A. Neutrophil apoptosis and hypoxia. Fiziol Zh. 2010;56:115-24. 
45. Chen HY, Lee YR, Chen RH. The functions and regulations of DAPK in cancer metastasis. Apoptosis. 2014;19:364-70.

46. S, Scheibe K, Erlenbach-Wuensch K, Neufert C, SchneiderStock R. Death-associated protein kinase: a molecule with functional antagonistic duality and a potential role in inflammatory bowel disease. Int J Oncol. 2015;47:5-15.

47. Karlic H, Herrmann H, Varga F, Thaler R, Reitermaier R, Spitzer $\mathrm{S}$, et al. The role of epigenetics in the regulation of apoptosis in myelodysplastic syndromes and acute myeloid leukemia. Crit Rev Oncol Hematol. 2014;90:1-16.

48. Nakav S, Cohen S, Feigelson SW, Bialik S, Shoseyov D, Kimchi $\mathrm{A}$, et al. Tumor suppressor death-associated protein kinase attenuates inflammatory responses in the lung. Am J Respir Cell Mol Biol. 2012;46:313-22.
49. Chuang YT, Fang LW, Lin-Feng MH, Chen RH, Lai MZ. The tumor suppressor death-associated protein kinase targets to TCR-stimulated NF-kappa B activation. J Immunol. 2008; 180:3238-49.

50. Grommes J, Soehnlein O. Contribution of neutrophils to acute lung injury. Mol Med. 2011;17:293-307.

51. El Kebir D, Jozsef L, Pan W, Wang L, Petasis NA, Serhan CN, et al. 15-epi-lipoxin A4 inhibits myeloperoxidase signaling and enhances resolution of acute lung injury. Am J Respir Crit Care Med. 2009;180:311-9.

52. Kuester D, Guenther T, Biesold S, Hartmann A, Bataille F, Ruemmele P, et al. Aberrant methylation of DAPK in longstanding ulcerative colitis and ulcerative colitis-associated carcinoma. Pathol Res Pract. 2010;206:616-24. 